\title{
Epigenetic Regulation of Neural Gene Expression and Neuronal Function
}

\author{
JIAN FENG, SHAUN FOUSE, AND GUOPING FAN
}

Department of Human Genetics, David Geffen School of Medicine, University of California at Los Angeles, Los Angeles, California 90095

\begin{abstract}
The development and function of the CNS requires accurate gene transcription control in response to proper environmental signals. Epigenetic mechanisms, including DNA methylation, histone modifications, and other chromatin-remodeling events, are critically important in mediating precise neural gene regulation. This review focuses on discussing the role of DNA methylation and histone modifications in neural lineage differentiation, synaptic plasticity and neural behavior. We postulate that DNA methylation- and histone modification-mediated gene regulation is not only important for neural cell differentiation but also crucial for high-order cognitive functions such as learning and memory. (Pediatr Res 61: 58R-63R, 2007)
\end{abstract}

$\mathrm{N}^{\mathrm{e}}$ eural development is composed of a cascade of genetic programs that precisely control stage-specific gene activities required for neural patterning, cell migration, and neuronal connectivity $(1,2)$. Proper regulation of stagespecific gene expression in the nervous system is not only controlled by the transcriptional machinery, but is also subject to modulation by epigenetic mechanisms such as DNA methylation, histone modifications, nucleosome and chromatin remodeling, and noncoding RNA-mediated posttranslational regulation $(3,4)$.

DNA methylation is catalyzed by a family of DNA methyltransferases (Dnmt) that include de novo (Dnmt 3a, Dnmt $3 \mathrm{~b}$ ) and maintenance methyltransferases (Dnmt1) (5,6). DNA methylation inhibits gene expression by either directly interfering with transcription factor binding to DNA (7) or recruitment of methyl-CpG binding domain (MBD) proteins which complex with histone deacetylase (HDAC) to transform chromatin to a repressive state (8) (Fig. 1). Recent studies indicate that DNA methylation is reversible $(9,10)$ and subject to dynamic regulation throughout embryogenesis and possibly the postnatal CNS (11). Consistent with its important role during development, mutations of Dnmts in mice all lead to embryonic or early postnatal lethality $(12,13)$.

While modification of DNA by methylation generally leads to gene silencing, posttranslational modifications of histone proteins including acetylation, methylation, phosphorylation,

Received November 17, 2006; accepted December 20, 2006.

Correspondence: Guoping Fan, Ph.D., Department of Human Genetics, David Geffen School of Medicine, University of California at Los Angeles, 695 Charles Young Drive South, Los Angeles, CA 90095; e-mail: gfan@mednet.ucla.edu

This work is supported by National Institutes of Health RO1 grants NS44405 and NS51411 (GF) and NRSA F31 MH70204 (SF)

J.F. and S.F. contributed equally to this work.

DOI: $10.1203 / p d r .0 b 013 e 3180457635$ ubiquitination, or sumoylation can lead to both gene activation and repression (14). One of the best-studied modifications is the acetylation status of lysine residues, a reversible process that is catalyzed by either HAT or HDAC. The addition of an acetyl group by a member of the HAT family conveys structural changes, as it decreases the interaction between the negatively charged DNA backbone and the positively charged histone tail. This decrease in interaction can lead to a less compacted nucleosome, which is open to transcription factor complexes. Therefore, histone acetylation is associated with increased gene transcription. Conversely, HDAC remove the acetyl group, potentially leading to a general repression of gene transcription. Methylation of histones is another form of epigenetic regulation that has heritable, long-term effects, but can be reversed as well. Studies in the last few years have found that methylation on histone $\mathrm{H} 3$ at lysine 4 (K4) is associated with transcriptional activation whereas the di- and tri-methylation on histone $\mathrm{H} 3$ at lysine 9 (K9) is indicative of transcriptional inhibition. Although it was previously thought that histone methylation was stable, enzymes that can demethylate histones have been discovered. PADI4, lysine-specific histone demethylase 1 (LSD1), and the JmjC-domain histone methylases (JHDM) can all remove methyl groups from histone residues $(15,16)$. This newly discovered mechanism for histone demethylation adds another wrinkle into the understanding of how histones regulate gene expression.

\section{DYNAMIC EXPRESSION OF DNA METHYLTRANSFERASES IN THE NERVOUS SYSTEM}

In mammals, DNA methylation is virtually exclusively at $\mathrm{CpG}$ dinucleotides and is catalyzed by a family of DNA methyltransferases including Dnmt1, Dnmt3a, and Dnmt3b. Dnmt1 expression is remarkably high in the embryonic nervous system, consistent with the proposed role for Dnmt1 in maintaining DNA methylation in dividing neural progenitor cells (17). However, it is unclear why Dnmt1, as a major maintenance DNA methyltransferase, is still expressed in postmitotic neurons in perinatal and adult CNS $(17,18)$. Brooks et al. (18) suggested that Dnmt1 expression in post-

\footnotetext{
Abbreviations: Dnmt, DNA methyltransferase; GR, glucocorticoid receptor; HAT, histone acetyl transferase; HDAC, histone deacetylase; LG-ABN, licking/grooming and arched-backed nursing; LTP, long-term potentiation; RTS, Rubinstein-Taybi syndrome; VPA, valproic acid
} 


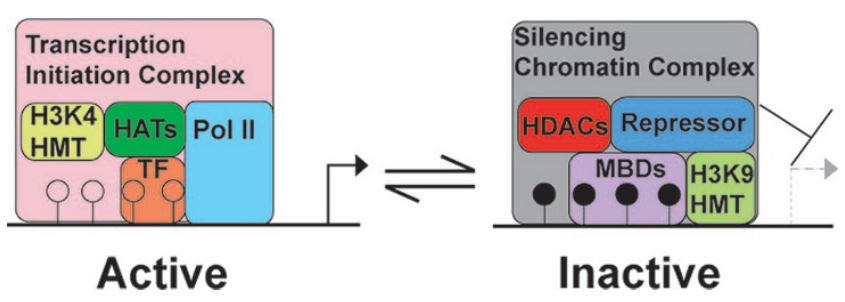

Figure 1. Schematic drawing of reversible regulation of gene expression through DNA methylation-related chromatin remodeling. Open circles represent unmethylated DNA and solid circles represent methylated DNA. HMT, histone methyltransferase; $M B D$, methyl-CpG binding domain proteins; $P o l$ $I I$, RNA polymerase II; $T F$, transcription factor.

mitotic neurons might serve to maintain DNA methylation after base-excision repair of the G:T mismatch that can occur upon deamination of the methylated cytosine. Alternatively, Dnmt1 may still be required for maintaining DNA methylation if methylation turnover occurs in adult postmitotic neurons. Coincidently, the level of DNA methylation is also higher in adult brain than in other tissues (19-21). Dnmt3a and Dnmt3b exhibit a complementary expression pattern in the developing nervous system $(11,22)$. Dnmt3b is mainly expressed in early embryonic cells and neural progenitor cells during neurogenesis. In contrast, Dnmt3a is predominantly expressed in later developmental stages and adult brain, which is detected in all neural cell lineages including neural precursor cells, maturing neurons, oligodendrocytes and a subset of astrocytes. In neuronal cells, Dnmt3a expression steadily increases and reaches a peak level around postnatal 2-3 wk, which are a critical window of neuronal maturation. In adult CNS neurons, relatively low levels of Dnmt3a proteins are detectable by Western blot analysis and immunohistochemistry $(11,22)$. A similar finding has been shown in the olfactory epithelia, where Dnmt3a is shown to be present in maturing olfactory receptor neurons (23). Taken together, the stage- and cell type-specific patterns of Dnmt3a and Dnmt3b suggest that these two enzymes play different roles in neural development and function.

The expression or enzymatic activity of Dnmt is also subject to active regulation under physiologic or pathologic conditions. Rampon et al. (24) found that Dnmt1 mRNA level was dramatically up-regulated in the mouse brain when animals were placed in an enriched environment for 3-6 h, suggesting a potential role for Dnmt1 in learning and memory. Endres et al. (25) demonstrated that levels of DNA methylation in the brain were actually increased upon ischemic injury, and this increase was partly dependent on Dnmt1 activity. Blocking Dnmt1 activity, either genetically or pharmacologically, is protective to the injured neurons, suggesting that a precise regulation of DNA methylation levels is important for neuronal survival (25). In patients suffering psychosis (bipolar disorder and schizophrenia), cortical interneurons appear to over express DNMT1 mRNA, which negatively correlates to the observed decrease in glutamic acid decarboxylase 67 (GAD67) mRNA in these cells (26). Although it is unclear whether deregulation of DNMT expression is a cause or a consequence of these pathologic conditions, the modulation of DNMT activity and expression argues for the potential changes of DNA methylation in association with neural injury or diseases.

\section{CONTROL OF NEURAL CELL DIFFERENTIATION BY DNA METHYLATION}

As the CNS develops, neural precursors of the subventricular zone first give rise to neurons, which migrate out to different layers of the cortex. This is followed by a switch that gives rise to astrocytes and oligodendrocytes. Maintaining proper control of gene expression is necessary for these transitions. Teter et al. (27) and Takizawa et al. (28) have shown that developmental demethylation of the GFAP gene promoter is correlated with the activation of GFAP gene transcription during astrogliogenesis. Furthermore, methylation of the $\mathrm{CpG}$ within the STAT3 binding site can block the association of activated STAT3 with the GFAP promoter, consistent with the model that DNA methylation represses GFAP expression (28). To address the function of Dnmt1 in the CNS, we have previously generated conditional mutant mice that are deficient in Dnmt1 exclusively in mouse CNS precursor cells or postmitotic neurons through conditional mutations (29). Dnmt1 deficiency in neural precursor cells causes global demethylation in the entire CNS and neonatal death due to respiratory failure (24), consistent with a critical role for DNA methylation in controlling vital CNS functions. The generation of conditional Dnmt1 mutant mice also provides us with a tool to identify neural genes that are regulated by DNA methylation in the CNS. Indeed, by using DNA microarrays to profile gene expression (our unpublished result), we found that STAT1 mRNA is significantly increased in the demethylated CNS (30). Because the JAK-STAT pathway is crucial for the timing of gliogenesis $(31,32)$, the elevated expression of STAT signal suggests that astroglial differentiation may be affected in Dnmt1-deficient brain. Subsequently, we demonstrated that the GFAP promoter is precociously demethylated in Dnmt1-deficient CNS. Moreover, the elevation of STAT signals, in concert with demethylation in glial genes, leads to precocious astrogliogenesis (30). Our findings provide a mechanism where DNA methylation controls the timing of astrogliogenesis through the regulation of STAT activation as well as the chromatin remodeling of glial marker genes such as GFAP. Nevertheless, many questions still remains as to how developmental demethylation occurs in the STAT1 and GFAP promoters. Is demethylation a passive process that requires DNA replication or is it an active process? If it is an active process, does it function through either a DNA glycosylase or some other unknown enzyme that can remove methyl groups without base repair? How is the timing of this demethylation regulated? Is it the result of extracellular signals or through an intrinsic clock mechanism?

\section{HISTONE MODIFICATIONS IN NEURONAL AND GLIAL DIFFERENTIATION}

In addition to alterations in DNA methylation, epigenetic modifications to histone tails can play important roles in lineage specification during differentiation of neural precursor cells. Recent work in multipotent adult neural progenitor cells 
has implicated an important role for the inhibition of histone deacetylation during neuronal differentiation. Hsieh et al. (33) showed that when adult rat neural progenitors were treated with valproic acid (VPA), a known HDAC inhibitor, a decrease in the proliferation of adult neural progenitors was coupled with an increase in neuronal differentiation without increasing gliogenesis. Upon examination of gene expression levels, an increase in NeuroD mRNA occurs after VPA treatment (33). Correspondingly, over-expression of NeuroD in neural progenitors resulted in increased neurons and reduced ability to differentiate into glial subtypes, similar to VPA treatment. When injected into the adult hippocampus, VPA resulted in a decrease in proliferation and an increase in neural differentiation (33). Taken together, these data suggest modifications to histone tails regulate gene expression during rat neural precursor differentiation.

In a similar study, work in neonatal rats has demonstrated the necessity for histone deacetylase activity for oligodendrocyte lineage progression (34). Treatment of oligodendrocyte progenitors with trichostatin A (TSA), another HDAC inhibitor, resulted in the blockage of differentiation in mature oligodendrocytes. Surprisingly, HDAC inhibition did not affect the maturation of type II astrocytes, as demonstrated by the presence of GFAP positive cells. In a later study, the same lab showed that the acetylation status of histones is an important timing mechanism for oligodendrocyte differentiation (35). Deacetylation of histone H3 by class I HDAC occurred during the onset of myelination, which happens within the first 2 wk of postnatal development. Subsequently, the mature oligodendrocytes acquire $\mathrm{H} 3$ lysine 9 methylation and are not affected by HDAC inhibitors. How histone deacetylation can push progenitors toward an oligodendrocyte fate is not fully understood, as de-acetylation is associated with gene repression. One model suggests that the genes responsible for differentiation have negative regulatory elements in their promoters that are only accessible in an acetylated state. Upon de-acetylation, the association of negative regulatory elements is blocked and the genes required for oligodendrocyte differentiation can be expressed. A second model hypothesizes that genes blocking oligodendrocyte differentiation are expressed due to their acetylated state, and, upon differentiation, deacetylation of histones leads to transcriptional repression and allows for the expression of downstream genes responsible for oligodendrocyte differentiation. The second model is consistent with the observed regulation of NeuroD via histone acetylation/de-acetylation in rat neural precursors (33).

\section{EPIGENETIC MECHANISMS IN NEURAL PLASTICITY, LEARNING, AND MEMORY}

Plasticity changes during physiologic stimuli such as neuronal activity or in response to environmental changes underlie behavioral tasks such as learning and memory. The plasticity changes in the CNS include the long-term structural change of synaptic connectivity dependent upon stable modulation of gene expression. We have previously postulated that regulation of activity-dependent neuronal gene expression involves DNA methylation and chromatin remodeling. Using the gene regulation of brain-derived neurotrophic factor (BDNF) as an example, we and others have shown that activity-dependent induction of BDNF expression in cortical neurons is accompanied with the dissociation of a repression complex including the methyl-CpG-binding domain protein MeCP2 and histone deacetylases $(36,37)$. We have demonstrated that a decrease in $\mathrm{CpG}$ methylation within the BDNF promoter may mediate sustained elevation of BDNF gene transcription in long-term culture of cortical neurons with depolarizing conditions (36). Since BDNF is a critically important gene for neuronal survival and plasticity, these results implicate that DNA methylation can influence neural plasticity through the regulation of activity-dependent neuronal genes.

A recent study with inhibitors of Dnmt in hippocampal slice cultures suggests that Dnmt inhibitors can block long-term potentiation (LTP) in the hippocampus (38). However, it is unclear whether the influence of Dnmt inhibitors on LTP is a direct pharmacological effect of suppressing the physiologic pathway for LTP or if it is mediated by methylation changes. With the availability of mutant mice that are deficient in Dnmt 1 or Dnmt3a/3b in the hippocampus, we may evaluate more accurately the involvement of DNA methylation in the regulation of synaptic plasticity directly. Using a conditional knockout approach, we recently generated viable mutant mice that are deficient for Dnmt1 exclusively in the cortex and hippocampus (Hutnick et al., unpublished results). With this strain of mutant mice, Golshi et al. (39) examined functional thalamocortical neurotransmission and found that thalamocortical LTP cannot be induced in slices from mutant mice. Demethylation in the cortex also blocked the development of somatosensory projection in the sensory cortex, consistent with the notion that normal methylation is required for the development of synaptic plasticity (39).

Long-lasting changes in synaptic plasticity are believed to be one of the mechanisms underlying learning and memory. The involvement of histone modification/chromatin remodeling in synaptic plasticity of learning and memory was first reported in Aplysia (40). Histone acetylation and deacetylation were shown to modulate the activation or inhibition of memory storage-related gene expression, respectively (40) (Fig. 2). Within a single sensory neuron, an excitatory transmitter serotonin could induce expression of CREB1 transcription factor (c-AMP response element binding protein 1). Chromatin immunoprecipitation assays showed that CREB1 recruits CBP (CREB binding protein, which has histone acetylase activity). Subsequently, through histone acetylation and the recruitment of transcriptional machinery, CREB1/CBP together leads to the activation of downstream gene C/EBP that is required for a form of long-term synaptic plasticity with increased synapse strength called long-term facilitation (40) (Fig. 2A). On the contrary, treatment of this sensory neurons with an inhibitory transmitter FMRFamide would cause the displacement of CREB1/CBP with repressor complex CREB2 (ATF4)/HDAC5 on the target C/EBP gene promoter, leading to the promoter deacetylation and inhibition of $\mathrm{C} / \mathrm{EBP}$ gene expression as well as subsequent switch of synaptic plasticity into long-term depression (40) (Fig. 2B). 

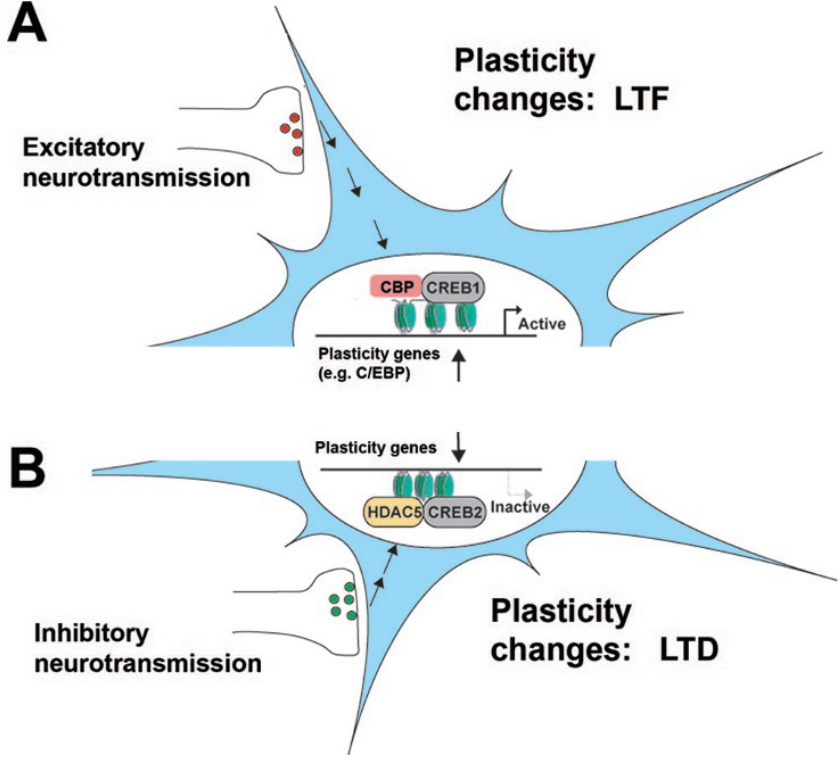

Figure 2. Histone modifications mediate alterations in neural gene expression and long-term neural plasticity. A schematic drawing of excitatory $(A)$ and inhibitory $(B)$ synaptic transmission in a sensory neuron in Aplysia that can lead to long-term synaptic plasticity changes such as LTF (long-term facilitation) and LTD (long-term depression) (40). Histone acetylation through HAT proteins (e.g. CBP) or de-acetylation by HDAC5 is involved in the stable alterations in the expression of the plasticity genes such as C/EBP

In humans, the mutation of the CBP gene is believed to be the cause of a mental retardation disease: Rubinstein-Taybi syndrome (41). As a coactivator of transcription, CBP has dual functions in mediating gene activation. First, CBP serves as a platform for recruiting other transcription factors to the transcriptional machinery. Second, CBP works as a histone acetyltransferase that alters chromatin structure. By using transgenic mouse models of RTS, the histone acetyltransferase activity of CBP was recognized as the critical component of memory consolidation (42-44). Long-term memory stabilization was impaired in one RTS mouse model possessing hippocampal specific expression of a mutant form of CBP lacking HAT activity (43). Either the suppression of transgene expression or HDAC inhibitor administration in adult mice could reverse the effect, both of which provided a potential option for future therapy. By using a haploinsufficiency form of the RTS mouse model, the memory deficit could also be ameliorated by enhancing the CREB-dependent gene expression, as well as inhibiting HDAC (42). These results suggest that both histone acetylation function of CBP and CREB coactivation are important for the memory formation. Within the multiple functional domains of CBP, perhaps the CREB-binding (KIX) domain is the one that is essential for long-term memory storage (45). In this case, recruitment of the transcriptional coactivator CBP via the KIX domain may select a set of genes under CREB regulation that are required for the long-term memory storage.

Whereas deficiency of chromatin remodeling would lead to problem with memory formation, it has been clearly demonstrated that changes in memory may induce histone modification changes as well. For example, contextual fear conditioning, a robust model of associative learning, can lead to both
$\mathrm{H} 3$ acetylation and $\mathrm{H} 3$ phosphorylation changes in the hippocampus (46). These histone modifications may possibly be regulated through the ERK/MAPK pathway, a key signaling cascade for hippocampal memory consolidation. But whether $\mathrm{H} 3$ acetylation and $\mathrm{H} 3$ phosphorylation play convergent or independent roles during the memory formation is still unclear.

\section{EPIGENETIC REGULATION OF NEURAL BEHAVIOR}

The early experience has a profound effect on adult patterns of behavior. For instance, initial parenting style can influence a child's future behavior and personality. One key question remaining to be answered is how the effects of early environmental factors on phenotype are maintained in the long-run. One interesting phenomenon is that levels of pup licking/ grooming and arched-back nursing (LG-ABN) by rat mothers within the first week after birth has a profound effect on the pups' stress response later in their adult lives. More specifically, the offspring of "high LG-ABN" mothers are less fearful and show more modest hypothalamic-pituitary-adrenal (HPA) responses to stress than the offspring of "low LG-ABN" mothers (47). In a cross-fostering experiment in which biologic offspring of a "low LG-ABN" mother are raised by a "high LG-ABN" mother, the "low LG-ABN" offspring will resemble the stress response of normal offspring of the "high LG-ABN" mother. This cross-fostering experiment implies the possibility that this behavioral effect is under control of nongenomic modulation (48). Correspondingly, the adult offspring of "high LG-ABN" mothers show increased hippocampal glucocorticoid receptor (GR) expression. To examine how early maternal LG-ABN behavior affects the pups' GR expression levels, Weaver et al. (49) found there is a dynamic change of the epigenome around the GR gene promoter region. The transcription factor NGFI-A binding site within the first exon of GR switched from an unmethylated state to a methylated status just after birth. Strikingly, over the critical period of the postnatal first week, exposure to "high LGABN" mothering caused one key $\mathrm{CpG}$ site to be demethylated, which did not happen under "low LG-ABN" maternal care. In addition, the histone surrounding the GR promoter region also became more acetylated under "high LG-ABN" mothering. As a result, both DNA demethylation and histone acetylation provided open access for NGFI-A to GR gene regulation. The sustained GR expression then maintained long-term modest stress response in the "high LG-ABN" mother-raised offspring. Most importantly, in adult rats, CNS administration of HDAC inhibitor reversed the stress response under "low LG-ABN" care. In contrast, providing a donor of methyl groups for DNA methylation also reversed stress response in "high LG-ABN" raised offspring (50). This not only proves the causal relationship between epigenetic modulation and long-term behavioral change, but also provides evidence that even in adult postmitotic neurons, DNA methylation and histone modification can be dynamic. Indeed, hundreds of genes have been found to be differentially regulated under specific maternal care, and modulating the epigenome could 
reverse the gene expression profile (51). This indicates that the epigenetic regulation of long-term behavior changes is probably a globally conserved event.

The role of histone modification in circadian rhythm also implies that epigenetic mechanisms can serve as a fine-tuned mechanism on the rhythmic behavioral change. A circadian rhythm is a roughly 24-h cycle in the physiologic processes of mammals. The mammalian circadian clock resides in neurons of the hypothalamic suprachiasmatic nucleus (SCN). A nighttime light exposure caused rapid induction of clock and the phase-shifting of the pacemaker, which is accompanied with gene expression change. Histone phosphorylation changes are observed within the same SCN neurons that show gene expression changes, suggestive of dynamic chromatin remodeling which may modulate the circadian rhythm (52). One characteristic of the circadian clock is its rhythmic expression of different sets of genes. Etchegaray et al. (53) showed that the promoter regions of the circadian related genes exhibited a rhythmic histone acetylation. The observed epigenetic modifications may indeed be a response to environmental stimuli like light, and this coordinate activation may modulate different circadian gene expression in a rhythmic pattern, which entrains the phase control of the behavioral outputs.

\section{EPIGENETIC DYSREGULATION IN NEUROPSYCHIATRIC DISORDERS}

Within the past decade, more and more human genetic diseases, in particular neuropsychiatric disorders, have been identified to be related to epigenetic dysregulation (54). For example, the neurodevelopmental disorder Rett Syndrome is caused by mutations in one of the MBD proteins, MeCP2, which is proposed to mediate gene-silencing effects of DNA methylation (55). The ICF (immunodeficiency, centromere instability, and facial anomaly) syndrome is caused by mutations in one of the de novo methyltransferases, DNMT3B, and a portion of ICF patients also exhibit features of mental retardation (56). Furthermore, dysregulation of DNA methylation and histone modifications is also associated with the complex psychiatric diseases such as bipolar and schizophrenia (26). In addition, a variety of epigenetic dysregulations are observed in classic imprinting disorders such as Angelman syndrome and Prader-Willi syndrome, as well as learning disability disorders Coffin-Lowry syndrome (mutations in Rsk2 for histone phosphorylation) and above mentioned Rubinstein-Taybi syndrome (CBP histone acetylase) (41,57-59). The association of neuropsychiatric disorders with epigenetic mechanisms underscores the importance of DNA methylation and histone modifications in neural development and function.

Meanwhile, epigenetic changes also appear during some pathologic brain responses, which include ischemia (25), addiction (60), depression (61), and seizure (62). A common thread in these disorders is that the pathologic etiology requires changes in neural plasticity. For example, cocaine induces neuro-adaptations through regulation of gene expression. Kumar et al. (60) hypothesize that cocaine administration could induce global level histone acetylation change within striatum, the major neural substrate for the addiction actions. Indeed, cocaine induced different histone modifications at different gene promoters. At the cFos gene promoter, $\mathrm{H} 4$ hyperacetylation was seen instantly after fast cocaine injection, whereas no histone modifications were seen with chronic cocaine administration, consistent with cocaine's ability to induce cFos acutely. In contrast, at the BDNF and Cdk5 promoters, genes that are induced by chronic cocaine, H3 hyperacetylation was observed with chronic cocaine only. This shows clearly that addiction induces neuroadaptations through epigenetic regulation of gene expression. Furthermore, it also provides evidence that individual gene expressions are associated with different epigenetic regulatory mechanisms.

\section{CONCLUSION}

Epigenetic gene regulation through DNA methylation and histone modifications has been shown to be a crucial mechanism for the development and function of the nervous system, ranging from cell differentiation to neuronal plasticity, from learning and memory to behavior. The deregulation of the epigenome could lead to various neuropsychiatric disorders. In response to ever-changing environments, the nervous system is required to make appropriate long-lasting changes at the level of neural circuitry and neurotransmission, which likely require stable gene expression to maintain these changes. Epigenetic mechanisms provide a means of dynamic regulation of gene expression over the relative static genome. Indeed, dynamic changes in DNA methylation and histone modifications not only take place in the dividing cells, but also seems to exist in the adult postmitotic neurons. Many challenging questions remain to be solved, such as what are the signaling cascades that induce the epigenetic change in the nervous system, and how the epigenome encodes in response to specific environmental stimuli. Emerging evidence begin to reveal the association of specific histone modifications with the particular functional states of the nervous system. For example, $\mathrm{H} 3$ hyperacetylation in the CNS follows chronic cocaine administration whereas $\mathrm{H} 4$ hyperacetylation happens after fast cocaine addiction (60); a contextual fear conditioning induces both $\mathrm{H} 3$ acetylation and $\mathrm{H} 3$ phosphorylation, which may have synergistic effects (46). Lastly, recent studies have identified many enzymes/activities in the nervous system that can reversibly modify DNA methylation or histone residues, thus yielding active or inactive chromatin remodeling for stable alterations in gene expression (Fig. 1). We envision that decoding the diverse epigenetic changes underlying neural development as well as neuronal gene regulation in complex behavior such as learning and memory will be an exciting endeavor in this postgenome era.

Acknowledgments. The authors thank Leah Hutnick and Michael Clark for their critical readings of this manuscript.

\section{REFERENCES}

\footnotetext{
1. Jessell TM, Sanes JR 2000 Development. The decade of the developing brain. Cur Opin Neurobiol 10:599-611

2. Gage FH 2002 Neurogenesis in the adult brain. J Neurosci 22:612-613
} 
3. Hsieh J, Gage FH 2005 Chromatin remodeling in neural development and plasticity. Curr Opin Cell Biol 17:664-671

4. Wu H, Sun YE 2006 Epigenetic regulation of stem cell differentiation. Pediatr Res 59:21R-25R.

5. Bestor TH 2000 The DNA methyltransferases of mammals. Hum Mol Genet 9:2395-2402

6. Robertson KD, Wolffe AP 2000 DNA methylation in health and disease. Nat Rev Genet 1:11-19

7. Watt F, Molloy PL 1988 Cytosine methylation prevents binding to DNA of a HeLa cell transcription factor required for optimal expression of the adenovirus major late promoter. Genes Dev 2:1136-1143

8. Fan G, Hutnick L 2005 Methyl-CpG binding proteins in the nervous system. Cell Res 15:255-261

9. Morgan HD, Dean W, Coker HA, Reik W, Petersen-Mahrt SK 2004 Activationinduced cytidine deaminase deaminates 5-methylcytosine in DNA and is expressed in pluripotent tissues: implications for epigenetic reprogramming. J Biol Chem 279:52353-52360

10. Jost JP, Oakley EJ, Zhu B, Benjamin D, Thiry S, Siegmann M, Jost YC 2001 5-Methylcytosine DNA glycosylase participates in the genome-wide loss of DNA methylation occurring during mouse myoblast differentiation. Nucleic Acids Res 29:4452-4461

11. Feng J, Chang H, Li E, Fan G 2005 Dynamic expression of de novo DNA methyltransferases Dnmt3a and Dnmt3b in the central nervous system. J Neurosci Res 79:734-746

12. Li E, Bestor T, Jaenisch R 1992 Targeted mutation of the DNA methyltransferase gene results in embryonic lethality. Cell 69:915-926

13. Okano M, Bell D, Haber D, Li E 1999 DNA methyltransferases Dnmt3a and Dnmt3b are essential for de novo methylation and mammalian development. Cell 99:247-257

14. Jenuwein T, Allis CD 2001 Translating the histone code. Science 293:1074-1080

15. Shi Y, Lan F, Matson C, Mulligan P, Whetstine JR, Cole PA, Casero RA, Shi Y 2004 Histone demethylation mediated by the nuclear amine oxidase homolog LSD1. Cell 119:941-953

16. Klose RJ, Kallin EM, Zhang Y 2006 JmjC-domain-containing proteins and histone demethylation. Nat Rev Genet 7:715-727

17. Goto K, Numata M, Komura JI, Ono T, Bestor TH, Kondo H 1994 Expression of DNA methyltransferase gene in mature and immature neurons as well as proliferating cells in mice. Differentiation 56:39-44

18. Brooks PJ, Marietta C, Goldman D 1996 DNA mismatch repair and DNA methylation in adult brain neurons. J Neurosci 16:939-945

19. Wilson VL, Smith RA, Ma S, Cutler RG 1987 Genomic 5-methyldeoxycytidine decreases with age. J Biol Chem 262:9948-9951

20. Tawa R, Ono T, Kurishita A, Okada S, Hirose S 1990 Changes of DNA methylation level during pre- and postnatal periods in mice. Differentiation 45:44-48

21. Ono T, Uehara Y, Kurishita A, Tawa R, Sakurai H 1993 Biological significance of DNA methylation in the ageing process. Age Ageing 22:S34-S43

22. Watanabe D, Uchiyama K, Hanaoka K 2006 Transition of mouse de novo methyltransferases expression from Dnmt3b to Dnmt3a during neural progenitor cell development. Neuroscience 142:727-737

23. MacDonald JL, Gin CS, Roskams AJ 2005 Stage-specific induction of DNA methyltransferases in olfactory receptor neuron development. Dev Biol 288:461-473

24. Rampon C, Tang YP, Goodhouse J, Shimizu E, Kyin M, Tsien JZ 2000 Enrichment induces structural changes and recovery from nonspatial memory deficits in CA1 NMDAR1-knockout mice. Nat Neurosci 3:238-244

25. Endres M, Meisel A, Biniszkiewicz D, Namura S, Prass K, Ruscher K, Lipski A, Jaenisch R, Moskowitz MA, Dirnagl U 2000 DNA methyltransferase contributes to delayed ischemic brain injury. J Neurosci 20:3175-3181

26. Veldic M, Guidotti A, Maloku E, Davis JM, Costa E 2005 In psychosis, cortical interneurons overexpress DNA-methyltransferase 1. Proc Natl Acad Sci U S A 102:2152-2157

27. Teter B, Osterburg HH, Anderson CP, Finch CE 1994 Methylation of the rat glial fibrillary acidic protein gene shows tissue-specific domains. J Neurosci Res 39:680693

28. Takizawa T, Nakashima K, Namihira M, Ochiai W, Uemura A, Yanagisawa M, Fujita N, Nakao M, Taga T 2001 DNA methylation is a critical cell-intrinsic determinant of astrocyte differentiation in the fetal brain. Dev Cell 1:749-758

29. Fan G, Beard C, Chen RZ, Csankovszki G, Sun Y, Siniaia M, Biniszkiewicz D, Bates B, Lee PP, Kuhn R, Trumpp A, Poon C, Wilson CB, Jaenisch R 2001 DNA hypomethylation perturbs the function and survival of CNS neurons in postnatal animals. J Neurosci 21:788-797

30. Fan G, Martinowich K, Chin MH, He F, Fouse SD, Hutnick L, Hattori D, Ge W, Shen Y, Wu H, ten Hoeve J, Shuai K, Sun YE 2005 DNA methylation controls the timing of astrogliogenesis through regulation of JAK-STAT signaling. Development 132:3345-3356

31. Bonni A, Sun Y, Nadal-Vicens M, Bhatt A, Frank DA, Rozovsky I, Stahl N, Yancopoulos GD, Greenberg ME 1997 Regulation of gliogenesis in the central nervous system by the JAK-STAT signaling pathway. Science 278:477-483

32. He F, Ge W, Zhu W, Becker-Catania S, Martinowich K, Wu H, Coskun V, Fan G, deVellis J, Sun Y 2005 A positive autoregulation loop of JAK- STAT signaling is part of the clock mechanism regulating astrogliogenesis. Nat Neurosci 8:616-625

33. Hsieh J, Nakashima K, Kuwabara T, Mejia E, Gage FH 2004 Histone deacetylase inhibition-mediated neuronal differentiation of multipotent adult neural progenitor cells. Proc Natl Acad Sci U SA 101:16659-16664

34. Marin-Husstege M, Muggironi M, Liu A, Casaccia-Bonnefil P 2002 Histone deacetylase activity is necessary for oligodendrocyte lineage progression. J Neurosci $22: 10333-10345$
35. Shen S, Li J, Casaccia-Bonnefil P 2005 Histone modifications affect timing of oligodendrocyte progenitor differentiation in the developing rat brain. J Cell Biol 169:577-589

36. Martinowich K, Hattori D, Wu H, Fouse S, He F, Hu Y, Fan G, Sun YE 2003 DNA methylation-related chromatin remodeling in activity-dependent BDNF gene regulation. Science 302:890-893

37. Chen WG, Chang Q, Lin Y, Meissner A, West AE, Griffith EC, Jaenisch R, Greenberg ME 2003 Derepression of BDNF transcription involves calciumdependent phosphorylation of MeCP2. Science 302:885-889

38. Levenson JM, Roth TL, Lubin FD, Miller CA, Huang IC, Desai P, Malone LM, Sweatt JD 2006 Evidence that DNA (cytosine-5) methyltransferase regulates synaptic plasticity in the hippocampus. J Biol Chem 281:15763-15773

39. Golshi P, Hutnick L, Schweizer F, Fan G 2007 Conditional Dnmt1 deletion in dorsal forebrain disrupts development of somatosensory barrel cortex and thalamocortical long-term potentiation. Thalamus Relat Syst, in press

40. Guan Z, Giustetto M, Lomvardas S, Kim JH, Miniaci MC, Schwartz JH, Thanos D, Kandel ER 2002 Integration of long-term-memory-related synaptic plasticity in volves bidirectional regulation of gene expression and chromatin structure. Cell 111:483-493

41. Petrij F, Giles RH, Dauwerse HG, Saris JJ, Hennekam RC, Masuno M, Tommerup N, van Ommen GJ, Goodman RH, Peters DJ, et al 1995 Rubinstein-Tayb syndrome caused by mutations in the transcriptional co-activator CBP. Nature 376:348-351

42. Alarcon JM, Malleret G, Touzani K, Vronskaya S, Ishii S, Kandel ER, Barco A 2004 Chromatin acetylation, memory, and LTP are impaired in CBP+/- mice: a model for the cognitive deficit in Rubinstein-Taybi syndrome and its amelioration. Neuron 42:947-959

43. Korzus E, Rosenfeld MG, Mayford M 2004 CBP histone acetyltransferase activity is a critical component of memory consolidation. Neuron 42:961-972

44. Wood MA, Kaplan MP, Park A, Blanchard EJ, Oliveira AM, Lombardi TL, Abel T 2005 Transgenic mice expressing a truncated form of CREB-binding protein (CBP) exhibit deficits in hippocampal synaptic plasticity and memory storage. Learn Mem 12:111-119

45. Wood MA, Attner MA, Oliveira AM, Brindle PK, Abel T 2006 A transcription factor-binding domain of the coactivator $\mathrm{CBP}$ is essential for long-term memory and the expression of specific target genes. Learn Mem 13:609-617

46. Chwang WB, O'Riordan KJ, Levenson JM, Sweatt JD 2006 ERK/MAPK regulates hippocampal histone phosphorylation following contextual fear conditioning. Learn Mem 13:322-328

47. Liu D, Diorio J, Tannenbaum B, Caldji C, Francis D, Freedman A, Sharma S, Pearson D, Plotsky PM, Meaney MJ 1997 Maternal care, hippocampal glucocorticoid receptors, and hypothalamic-pituitary-adrenal responses to stress. Science 277:1659-1662

48. Francis D, Diorio J, Liu D, Meaney MJ 1999 Nongenomic transmission across generations of maternal behavior and stress responses in the rat. Science 286:11551158

49. Weaver IC, Cervoni N, Champagne FA, D’Alessio AC, Sharma S, Seckl JR, Dymov S, Szyf M, Meaney MJ 2004 Epigenetic programming by maternal behavior. Nat Neurosci 7:847-854

50. Weaver IC, Champagne FA, Brown SE, Dymov S, Sharma S, Meaney MJ, Szyf M 2005 Reversal of maternal programming of stress responses in adult offspring through methyl supplementation: altering epigenetic marking later in life. J Neurosci 25:11045-11054

51. Weaver IC, Meaney MJ, Szyf M 2006 Maternal care effects on the hippocampal transcriptome and anxiety-mediated behaviors in the offspring that are reversible in adulthood. Proc Natl Acad Sci U S A 103:3480-3485

52. Crosio C, Cermakian N, Allis CD, Sassone-Corsi P 2000 Light induces chromatin modification in cells of the mammalian circadian clock. Nat Neurosci 3:12411247

53. Etchegaray JP, Lee C, Wade PA, Reppert SM 2003 Rhythmic histone acetylation underlies transcription in the mammalian circadian clock. Nature 421:177-182

54. Egger G, Liang G, Aparicio A, Jones PA 2004 Epigenetics in human disease and prospects for epigenetic therapy. Nature 429:457-463

55. Amir RE, Van den Veyver IB, Wan M, Tran CQ, Francke U, Zoghbi HY 1999 Rett syndrome is caused by mutations in X-linked MECP2, encoding methyl-CpGbinding protein 2. Nat Genet 23:185-188

56. Xu GL, Bestor TH, Bourc'his D, Hsieh CL, Tommerup N, Bugge M, Hulten M, Qu X, Russo JJ, Viegas-Pequignot E 1999 Chromosome instability and immunodeficiency syndrome caused by mutations in a DNA methyltransferase gene. Nature 402:187-191

57. Nicholls RD, Saitoh S, Horsthemke B 1998 Imprinting in Prader-Willi and Angelman syndromes. Trends Genet 14:194-200

58. Goldstone AP 2004 Prader-Willi syndrome: advances in genetics, pathophysiology and treatment. Trends Endocrinol Metab 15:12-20

59. Hanauer A, Young ID 2002 Coffin-Lowry syndrome: clinical and molecular features. J Med Genet 39:705-713

60. Kumar A, Choi KH, Renthal W, Tsankova NM, Theobald DE, Truong HT, Russo SJ, Laplant Q, Sasaki TS, Whistler KN, Neve RL, Self DW, Nestler EJ 2005 Chromatin remodeling is a key mechanism underlying cocaine-induced plasticity in striatum. Neuron 48:303-314

61. Tsankova NM, Berton O, Renthal W, Kumar A, Neve RL, Nestler EJ 2006 Sustained hippocampal chromatin regulation in a mouse model of depression and antidepressant action. Nat Neurosci 9:519-525

62. Tsankova NM, Kumar A, Nestler EJ 2004 Histone modifications at gene promoter regions in rat hippocampus after acute and chronic electroconvulsive seizures. J Neurosci 24:5603-5610 